\section{As estratégias de luta simbólica para a formação da enfermeira visitadora no início do século XX}

\section{The strategies of the symbolic struggle for the training of the visiting nurse in the early twentieth century}

\section{Lílian Fernandes Arial Ayres}

Professora-assistente do Departamento de Medicina e Enfermagem/Universidade Federal de Viçosa. Rua Teixeiras, 135/202

36570-000 - Viçosa - MG - Brasi

liliayresenf@yahoo.com.br

Wellington Mendonça de Amorim

Professor adjunto da Escola de Enfermagem Alfredo Pinto (EEAP)/ Universidade Federal do Estado do Rio de Janeiro (Unirio). Rua Dr. Xavier Sigaud, 290. Biblioteca Setorial 22290-180 - Rio de Janeiro - RJ - Brasil

amorimw@gmail.com

Teresa Cristina de Carvalho Piva

Professora adjunta do Centro Universitário Celso Lisboa e do Programa de Pós-graduação em Educação Matemática/ Universidade Castelo Branco.

Rua Professor Gastão Bahiana, 114/404 22071-030 - Rio de Janeiro - RJ - Brasil

teresa.piva@yahoo.com.br

Fernando Rocha Porto

Professor adjunto da EEAP/Unirio. Rua Dr. Xavier Sigaud, 290. Biblioteca Setorial 22290-180 - Rio de Janeiro - RJ - Brasil

ramosporto@openlink.com.br

Recebido para publicação em novembro de 2010. Aprovado para publicação em fevereiro de 2012.
AYRES, Lílian Fernandes Arial et al. As estratégias de luta simbólica para a formação da enfermeira visitadora no início do século XX. História, Ciências, Saúde - Manguinhos, v.19, n.3, jul.-set. 2012, p.861-881.

Resumo

Com base na perspectiva históricosocial, o objeto deste estudo documental consistiu nas estratégias de luta simbólica para a formação de agentes de visitação domiciliar nos Cursos de Enfermeiras Visitadoras da Cruz Vermelha Brasileira e do Departamento Nacional de Saúde Pública, no Rio de Janeiro (DF), com repercussão no Departamento de Saúde e Assistência de Pernambuco, entre 1920 e 1926. Adotamos como referencial teórico o pensamento do sociólogo Pierre Bourdieu, evidenciando uma luta simbólica no campo da saúde pública entre os sanitaristas Amaury de Medeiros e José P. Fontenelle e a enfermeira de saúde pública Ethel Parsons, para analisar quem seria responsável pela autoridade e competência científica da formação das enfermeiras visitadoras.

Palavras-chave: história da enfermagem; tuberculose; enfermagem em saúde comunitária.

\section{Abstract}

Based on the historical and social perspective, the scope of this documentary study were the strategies of the symbolic struggle for the training of agents in home visitation in the Courses for Visiting Nurses of the Brazilian Red Cross and the National Department of Public Health in Rio de Janeiro (Federal District), with repercussions in the Department of Health and Welfare of the State of Pernambuco between 1920 and 1926. We adopted the thinking of sociologist Pierre Bourdieu as a theoretical benchmark, showing the symbolic struggle in the field of public health between sanitarians Amaury de Medeiros and José P. Fontenelle and public health nurse Ethel Parsons, to analyze who was responsible for the scientific authority and competence of the training of visiting nurses.

Keywords: history of nursing; tuberculosis; community health nursing. 
$\mathrm{D}$ perspectiva da história social, por meio da análise documental e apoiados no pensamento do sociólogo Pierre Bourdieu, discutimos as estratégias de luta simbólica e as alianças empreendidas pelos agentes Amaury de Medeiros, José P. Fontenelle e Ethel Parsons para a estruturação dos Cursos de Enfermeiras Visitadoras desenvolvidos pela Cruz Vermelha Brasileira, pelo Departamento Nacional de Saúde Pública (DNSP) e pelo Departamento de Saúde e Assistência (DSA) de Pernambuco, no período compreendido entre 1920 e 1926.

Para o desenvolvimento do referido estudo, utilizamos as noções de campo, capital cultural e poder simbólico. Segundo Bourdieu (2007), o campo é um espaço multidimensional de objetivação dos jogos de forças e de lutas. Nele estão inseridos os agentes e as instituições que ocupam posições nessa estrutura, orientando suas tomadas de decisão de acordo com os recursos de que dispõem. Neste estudo, consideramos o campo da saúde pública, com destaque para o espaço social do DNSP e da Cruz Vermelha Brasileira no Rio de Janeiro, ${ }^{1}$ com repercussão no DSA de Pernambuco - espaços de atuação dos sanitaristas e cientistas que se posicionavam como porta-vozes da formação de enfermeiras visitadoras.

Dos agentes sociais que compunham o campo da saúde pública no Rio de Janeiro, foram considerados as enfermeiras visitadoras, os médicos sanitaristas e um grupo de enfermeiras norte-americanas, com ênfase nos movimentos táticos de Amaury de Medeiros, J.P. Fontenelle e da enfermeira de saúde pública Ethel Parsons. A estrutura do campo ou a posição em que os agentes estão distribuídos nesse espaço é definida pelo capital cultural que cada agente engajado possui, bem como por suas estratégias (Bourdieu, 2004).

No campo da saúde pública, Amaury de Medeiros e José P. Fontenelle detinham um capital determinante nas condições que ambos apresentaram para divulgar uma visão de mundo social que, na época, fundamentou o modo de ver a formação de enfermeiras. As enfermeiras visitadoras constituíram-se em agentes emergentes necessários à saúde pública, imposta pelas forças simbólicas. Ao resultarem das lutas entre os agentes e suas ideologias, foram-lhes assegurados a dominação e o poder simbólico sobre as mesmas, poder esse, segundo Bourdieu (2007, p.8) entendido como "invisível, o qual só pode ser exercido com a cumplicidade daqueles que não querem saber que lhe estão sujeitos ou mesmo que o exercem".

Os fatos aqui narrados resultaram na redistribuição do poder no campo da saúde pública e no surgimento de traços diversos na identidade de formação da enfermagem de saúde pública no Rio de Janeiro (DF) e no Recife (PE). Com este estudo, pretendemos jogar luz sobre a influência dos sanitaristas Amaury de Medeiros e José P. Fontenelle no ensino da enfermagem brasileira e sobre sua luta pela manutenção do domínio e do controle do Curso de Enfermeiras Visitadoras. Por último, destacamos de que modo o processo de trabalho da enfermeira visitadora promoveu desdobramentos simbólicos dentro e fora do campo da saúde pública do Rio de Janeiro (DF).

\section{A trajetória e a ideologia dos agentes Amaury de Medeiros e José P. Fontenelle}

No fim do século XIX, a noção de higiene acompanhou o desenvolvimento das ciências naturais. Acreditava-se que a origem das doenças que acometiam o homem estava 
relacionada com os fatores ambientais. Sendo assim, as políticas sanitárias adotadas baseavam-se na questão do saneamento, da ventilação das casas e das indústrias. Com a inclusão de outras áreas como microbiologia, parasitologia e engenharia no campo da saúde pública, descobriu-se haver mais um fator causal para explicar um grupo de doenças relacionadas com os microrganismos. Dessa forma, o caminho para combater determinadas doenças e prevenir o contágio seria feito via a educação sanitária. As políticas sanitárias começaram, assim, a ter como base propriamente científica a higiene moderna. Novos modelos de atuação na saúde foram surgindo no início do século XX. Segundo Fontenelle (1922, p.447), a evolução da higiene pública deu-se em três momentos:

$1^{\circ}$, aquele em que a Higiene estava reduzida aos cuidados com o meio ambiente, tido, então, como a causa de todos os males que atormentam o homem, resumindo-se os trabalhos de Saúde Pública nas questões de saneamento geral;

$2^{\circ}$, aquele em que foram acrescidos, às preocupações com a ambiência, os cuidados com as pessoas infectantes, fonte das doenças transmissíveis, de onde se difundem, por vários modos, para alcançar os indivíduos sãos;

$3^{\circ}$, finalmente, aquele em que agora estamos, e que reconhece, além do mais, a necessidade de pôr os indivíduos nas melhores condições de saúde e de capacidade de trabalho, ensinando e propagando as normas da Higiene perfectiva e profilática.

Medeiros (1924, p.20) complementa:

O momento que atravessamos no mundo, em que por toda parte se sente uma mudança radical e violenta nos princípios; em que o antigo continente, em ebulição socialista, se reconstrói, nós, que apenas estamos em início, precisamos pensar, desde já, seriamente, nas bases seguras da nossa construção ... É, portanto, para a higiene e para a cultura que devemos voltar as nossas vistas, para que daqui a alguns anos, não sejamos esta raça débil e multiforme, mas nos cristalizemos em um tipo de resistência forte e capaz, pela saúde e pela energia, pela inteligência e pela instrução, de contribuir para a marcha...

Depreendemos, assim, que, no que se refere à trajetória profissional dos agentes, José P. Fontenelle e Amaury de Medeiros se baseavam nos princípios da higiene. O primeiro acreditava que a ausência da educação havia sido um problema central na saúde pública do Brasil, sendo fundamental a propagação das normas de higiene à população. Já Amaury de Medeiros refere-se a uma nova cultura sanitária. Nesta última, a saúde pública deveria embasar-se na área de conhecimento da higiene visando à construção de bases sólidas para a sociedade brasileira. Além disso, no discurso de Amaury de Medeiros, é possível identificar que a higiene moderna estava articulada com a eugenia em que ambos os movimentos se baseavam para transformar em realidade o ideal de tornar o Brasil uma grande nação.

Sendo assim, os dois sanitaristas defendiam a tese de que, por meio da educação sanitária, o desenvolvimento de uma consciência individual deveria estar presente nos serviços sanitários. Desse modo, a higiene moderna foi considerada um campo de conhecimento que deveria ser a base das diretrizes da política sanitária. Segundo Merhy (1987), no entanto, as relações sociais do agente e os seus saberes foram direcionados por um modelo médico sanitário vigente na época. Neste último, as ações sanitárias visavam à consciência do indivíduo, predominando o cunho educativo, apesar de o modelo ter igualmente um caráter impositivo. 
Os discursos desses agentes os envolveram numa luta simbólica. Seu objetivo era impor a definição de mundo social de acordo com os interesses em jogo e conforme a higiene moderna. A crença nessa ideologia serviu, primeiramente, aos interesses particulares desses sanitaristas, porém, logo se universalizou, tornando-se comum aos outros e legitimando tal pensamento no campo da saúde pública. Manteve-se, assim, um discurso dominante que tendeu a impor como natural uma ordem estabelecida (Bourdieu, 2007).

Desse modo, os agentes Amaury de Medeiros e J.P, Fontenelle, através de seus discursos, baseados na ideologia da higiene moderna, objetivaram mobilizar o maior número possível de pessoas da sociedade civil, isto é, a elite médica sanitária, os trabalhadores e a classe média urbana, incluindo as mulheres, com o intuito de garantir uma mobilização duradoura, com o maior número de seguidores, na qual todos passassem a ter a mesma visão social, legitimando assim os ideais da higiene moderna.

\section{A tuberculose e a educação sanitária}

Com o progresso da concepção de higiene e diante do quadro sanitário vivenciado pelo Rio de Janeiro (DF) - principalmente as altas taxas de morbimortalidade da tuberculose - mostrou-se necessária a reformulação das tecnologias das práticas de saúde. Fontenelle (1922, p.450) destacou a esse respeito:

\footnotetext{
Para isso, aconselhava preferência às medidas diretas de profilaxia, que constituem a parte propriamente sanitária do problema, atacando o mal em suas próprias fontes, pelo combate ao contágio, em vez do emprego dos meios indiretos, que atuariam sobre a morada, a alimentação e o trabalho dos indivíduos, e que formam o lado social da luta contra a tuberculose. Nesse sentido, pôs em evidência a importância das enfermeiras de Higiene, recomendando a criação de um corpo dessas funcionárias.
}

Durante muitos anos, a tuberculose foi a grande responsável pela mortalidade em vários lugares do mundo, o Brasil incluído. No Rio de Janeiro (DF) não foi diferente. O impacto sobre a população foi intenso, essa doença sendo a maior responsável pela mortalidade na região, só sendo sobrepujada por outra em situação de epidemia. Com o desenvolvimento científico, os sanitaristas sabiam que a probabilidade de disseminação da tuberculose seria maior em lugares com péssimas condições de higiene e ventilação e em aglomerações urbanas (Nascimento, 2002).

O cenário do Rio de Janeiro (DF) era catastrófico, o que favoreceu a propagação da tuberculose, principalmente entre a população mais pobre e os trabalhadores. $\mathrm{O}$ índice de morbimortalidade vinculado a essa doença acompanhou o processo de urbanização, modernização e industrialização da cidade.

Apesar da prevalência da tuberculose, os governantes pouco fizeram em relação ao quadro sanitário instalado. Uma tentativa a se destacar foi a de Plácido Barbosa, delegado sanitário da Diretoria Geral de Saúde Pública (DGSP), que teve a oportunidade de ir aos Estados Unidos e conhecer os programas de combate à tuberculose. Quando voltou ao Brasil, apresentou um relatório com um plano de luta contra essa doença, no qual podemos destacar: 1) reformar o regulamento da DGSP, considerado ineficiente, e incluir medidas contra o escarro, regulamentando e fiscalizando a expectoração dos doentes com tuberculose; 2) criar uma 
inspetoria de profilaxia da tuberculose; 3) elaborar propagandas e promover a decretação das leis indispensáveis e gerir todos os serviços relativos a esse problema; e 4) criar o serviço de vigilância higiênica das pessoas com tuberculose em domicílio, para o ensino da higiene antituberculose, a instrução sobre os meios de cura ao ar livre e a fiscalização. Esse serviço seria feito por inspetores médicos e subalternos (Fontenelle, 1922).

Tal programa constituiu uma tentativa de luta contra a tuberculose no que tange às iniciativas do governo federal. Ficou clara a importância da criação de um departamento específico e com autonomia suficiente para determinar leis sanitaristas. Outro aspecto fundamental diz respeito ao cuidado domiciliar dispensado aos doentes de tuberculose, promovido por médicos e subalternos, bem como à utilização da educação como medida de prevenção e combate a essa doença. O relatório produzido por José P. Fontenelle (1922), contudo, não evidenciou quem seriam esses subalternos. Acreditamos tratar-se de guardas sanitários ou, então, de um novo agente formado para realizar a visita domiciliar.

O relatório supracitado ficou apenas no papel e nada mudou no cenário das altas taxas de tuberculose. Os médicos consideravam que o problema deveria ser urgentemente combatido para reduzir a mortalidade e a morbidade por conta da doença. Merece destaque a instituição filantrópica Liga Brasileira Contra a Tuberculose (LBCT), criada para implantar medidas de profilaxia e cura da enfermidade. A LBCT criou sanatórios e dispensários próprios que tiveram um papel essencial no combate à mesma (Nascimento, 2002).

Nesses espaços, as formas de atuação no combate à tuberculose eram a educação sanitária e a coerção. Os doentes eram separados em dois grupos: o primeiro, considerado não produtivo; e o segundo, o produtivo, formado por indivíduos que ainda conseguiam trabalhar. No primeiro, deveria ocorrer o isolamento hospitalar ou domiciliar. Ficava a cargo das autoridades sanitárias, que usavam a modalidade da coerção, exigindo que se cumprissem as ordens relacionadas ao isolamento e à desinfecção dos escarros. Já no segundo grupo, mostrou-se necessária a criação de uma seção educativa por meio das monitoras de higiene ou enfermeiras visitadoras (Fontenelle, 1941).

J.P. Fontenelle ressaltava o valor das enfermeiras visitadoras, sustentando que elas, os guardas sanitários e os auxiliares técnicos que constituiriam o quadro técnico subalterno deveriam substituir parcialmente o número excessivo de médicos no serviço sanitário (Fontenelle, 1922). O mesmo autor acrescenta ainda: "Foi nessa peregrinação - de rua em rua, de casa em casa, de quarto em quarto, de pessoa em pessoa - com paciência e com bondade que comecei a perceber que, decerto, isso não era propriamente serviço para médico" (Fontenelle, 1941, p.5).

Segundo J.P. Fontenelle, era preciso aumentar o número de subalternos convenientemente preparados e reduzir o quantitativo de médicos para o exercício da visita domiciliar. Depreendemos daí que esse trabalho, pouco científico e técnico, foi delegado assim para a enfermeira visitadora, o que ampliou a presença do trabalho feminino no campo da saúde pública. Desse modo, a mulher passa a assumir papéis antes reservados aos homens, devido ao conjunto de transformações sociais, políticas, culturais e econômicas. Além disso, a rígida distinção de tarefas a elas atribuídas e aos homens já não se adequava às transformações que ocorreram na sociedade, como ressalta Paicheler (1995). 
Ademais, era por meio da visita domiciliar que a enfermeira visitadora fortaleceria o vínculo com a família e promoveria a mudança dos padrões de comportamento - a partir das ações de educação sanitária, vigilância sanitária e avaliação das relações familiares. Ainda por meio dessas ações, com base no conhecimento da higiene moderna, a agente promoveria uma consciência sanitária individual e coletiva e, consequentemente, a redução da contaminação e da proliferação da tuberculose (Medeiros, 1924; Fontenelle, 1941).

Vale ressaltar que Amaury de Medeiros defendeu serem as mulheres as agentes ideais para realizar a visita domiciliar, como demonstra o fragmento a seguir: "Vencendo pela doçura, convencendo com as delicadezas tão peculiares às mulheres, dominando com os supremos recursos sutis e inexcedíveis de um sexo que consegue governar com queixas o vencido, é a visitadora o elemento decisivo para implantar os hábitos higiênicos" (Medeiros, 1924, p.43).

Ressaltamos aqui o processo por meio do qual são destacadas as características condizentes ao sexo feminino. Espera-se da enfermeira que ela seja doce, bondosa, dedicada, servil, abnegada e obediente. Esses atributos estão em consonância com aquilo que os pais, o marido e a sociedade almejavam de uma mulher. Essas "qualidades" dadas, que reforçavam a dominação masculina (dos médicos) sobre as enfermeiras, estavam introjetadas em suas mentes e funcionavam como um esquema de percepção, pensamento e ação (Bourdieu, 1999).

Segundo Leite (1984), o gênero feminino começou a conquistar o espaço público através de trabalhos caracterizados como atividades domésticas. Sendo assim, a mulher não concorria com o gênero masculino, uma vez que as profissões a ela atribuídas representavam uma extensão das atividades dos lares, junto aos filhos, ao marido e à família. Dessa forma, os sanitaristas acreditavam que sua presença nos domicílios alheios era uma vantagem, uma vez que as aptidões do gênero feminino o tornavam ideal para trabalhar com a coletividade dentro do seio familiar.

Diante disso, a questão da tuberculose como problema de saúde pública e a introdução da educação sanitária como elemento fundamental para a formação de uma consciência sanitária individual e coletiva proporcionaram o nascimento de sujeitos sociais. Dentre eles destaca-se a enfermeira visitadora, considerada um agente-chave para o desempenho desse papel.

\section{A formação das enfermeiras visitadoras}

A demanda da população carioca diante do problema da tuberculose levou duas instituições distintas - e que ocupavam o mesmo espaço geopolítico - a instituir cursos para formação de agentes visando capacitá-los em atividades de visitação domiciliar para atender aos enfermos. Cabe destacar que não encontramos indícios documentais de que já existissem enfermeiras visitadoras no Rio de Janeiro (DF) no final da década de 1910.

Conforme o boletim da Liga das Sociedades da Cruz Vermelha (League, 1921, p.66), na parte sobre a Campanha Nacional contra a Tuberculose: "A introdução no Brasil de visitadoras de saúde é devida à Cruz Vermelha". Coube ao integrante da Cruz Vermelha Brasileira, Amaury de Medeiros instituir um Curso de Enfermeira Visitadora. 
Amaury de Medeiros, jovem sanitarista, reconhecido como grande administrador sanitário, o "Oswaldo Cruz de Pernambuco", tinha como um dos princípios de sua vida profissional o aperfeiçoamento técnico do pessoal inserido em seu meio de trabalho (Oliveira, 1975). Ele via na enfermeira visitadora um elemento essencial no combate a inúmeras doenças, com destaque para a tuberculose, situação na qual desempenharia o papel de professora de higiene, disseminando informações seguras em relação ao cuidado à saúde do indivíduo. Em relação a essas agentes, Amaury de Medeiros (1924, p.44) posicionava-se do seguinte modo:

\footnotetext{
Vão espalhar estes conhecimentos, vão incuti-los no ânimo do povo e conseguirão, por certo, evitar muitos males que vivem à custa da ignorância ou da incúria... Eu vos darei um exemplo: está provado que, assistido e aconselhado por uma visitadora, um tuberculoso pode tornar-se inofensivo. Sabida, porém, a impossibilidade de isolar nos hospitais todos os tuberculosos contagiantes, só a visitadora poderá resolver o problema da luta contra a disseminação domiciliar que é a causa habitual da terrível doença.
}

Para Amaury de Medeiros, a educação sanitária deveria ser a base das práticas de saúde, e as enfermeiras visitadoras, por sua vez, seriam as instrutoras nos lares. Através delas, as famílias mudariam seus hábitos de vida, adquirindo uma consciência sanitária, o que promoveria a construção de indivíduos melhores, acabando com a imagem de uma raça doente e fraca.

Outro ponto a se destacar no seu discurso diz respeito ao isolamento dos doentes acometidos pela tuberculose. Diante da carência de sanatórios e de hospitais especializados nessa doença no Rio de Janeiro (DF), no início do século XX, era praticamente impossível isolar os enfermos, devido às altas taxas de casos novos e antigos. É nesse contexto que ganha relevância a presença da enfermeira visitadora: ao realizar a visita domiciliar, ela consegue conter os bacilos da tuberculose através de orientações higiênicas que minimizam a disseminação da doença. Entretanto, para desempenhar essa atribuição, era necessária uma capacitação diferenciada.

Sendo assim, aproveitando-se da posição de diretor do Departamento de Profilaxia contra a Tuberculose da Cruz Vermelha Brasileira e de líder da Cruzada Nacional Contra a Tuberculose, e acreditando em seus ideais, Amaury de Medeiros criou o Curso de Enfermeiras Visitadoras, por meio de conferências publicadas em revistas como a Revista Brazil-Medico e a Revista da Semana. ${ }^{2}$ A respeito do curso, anunciado em 10 de julho de 1920, Medeiros (1924, p.41) declarou: "Tive a honra de organizar o primeiro curso de visitadoras da saúde pública, com a assistência das senhoras da melhor sociedade do Rio".

Salientamos que a divulgação do nome e dos feitos do sanitarista em revistas conferiulhe certo prestígio e reconhecimento público, dotando-o portanto das condições necessárias para ascender no campo da saúde pública no Rio de Janeiro (DF). Sua ascensão foi impulsionada pelo capital cultural que acumulou não somente durante sua incipiente trajetória profissional na Capital Federal, mas também nas relações políticas que conseguiu estabelecer na Cruz Vermelha Brasileira.

Ademais, naquele momento, Amaury de Medeiros ocupava a posição de porta-voz autorizado, o que lhe conferiu o direito à palavra, o prestígio e o poder de autoridade na 
Cruz Vermelha Brasileira. Segundo Bourdieu (2004, p.167), o porta-voz é aquele "investido do pleno poder de agir e de falar em nome do grupo que ele produz pela magia do slogan, da palavra de ordem, da ordem e por sua simples existência enquanto encarnação do grupo".

O Curso de Enfermeira Visitadora estava inserido na proposta da Cruzada Nacional Contra a Tuberculose, possuindo plena autonomia administrativa e financeira, e contando com o apoio do governo federal, com uma quota do imposto de caridade da Alfândega, de acordo com o DNSP (Cruz Vermelha Brasileira, 1923). Isso caracterizou a ampliação das alianças entre tais repartições.

Apesar do estreitamento das relações entre o DNSP e a Cruz Vermelha Brasileira, no decorrer da análise, percebemos que, conforme explicitado no trecho a seguir, Amaury de Medeiros (1924, p. 42) teve dificuldades para sustentar discussões em favor das enfermeiras visitadoras, mesmo no campo da saúde pública: "No Rio de Janeiro, tive de sustentar discussões mesmo no meio médico; não admira, pois, que tenhais de ouvir, no exercício de vossa delicada missão, os mais descabidos comentários, até que os frutos de vossa atividade esclareçam os ignorantes, convençam os preguiçosos e a estes dominem, porque não conseguireis nunca vencer os maldizentes, cujas, censuras vos devem incentivar, como um sinal positivo de que estais no bom caminho".

Esse depoimento explicita o fato de Amaury de Medeiros ter enfrentado dificuldades para demarcar e legitimar um espaço no campo da saúde pública para as enfermeiras visitadoras. Era forte a oposição de alguns médicos à entrada dessas agentes. De acordo com Pereira Neto (2001), havia duas opiniões recorrentes sobre elas. A primeira enaltecia a figura dessas mulheres, considerando-as fundamentais para a luta contra a tuberculose, já que, uma vez realizado o Curso de Enfermeiras Visitadoras, elas dominariam o conhecimento necessário para melhor cuidar e convencer. Em contrapartida, na segunda corrente, os médicos declaravam que as enfermeiras visitadoras seriam virtuais concorrentes ao seu monopólio, exigindo que fossem subordinadas ao médico e que tivessem suas ações por eles limitadas.

Esse sentimento de perda de espaço ou de poder no campo da saúde pública pode ser explicado pelo fato de, naquela época, a visita domiciliar constituir um território praticamente exclusivo do médico. Até então, só ele estabelecia as regras e obtinha o controle do cuidado do doente e de sua família. Com a entrada da enfermeira visitadora nos lares, os médicos certamente disputariam um lugar nesse ambiente, perdendo parte de seu espaço no campo. Além disso, a entrada da mulher no meio familiar era mais tranquila e aceita, devido aos costumes da sociedade da época.

Cabe destacar que, conforme os documentos encontrados, a diligência do Curso de Enfermeira Visitadora da Cruz Vermelha Brasileira materializou-se apenas uma vez, no período compreendido entre 1920 e 1922. Em dezembro de 1922, Amaury de Medeiros deixou o cargo na Cruz Vermelha Brasileira (Órgão Central) para assumir a posição de diretor do Departamento de Higiene de Pernambuco, onde, posteriormente, foi nomeado para o Departamento de Saúde e Assistência de Pernambuco (DAS) (Medeiros, 1924).

Medeiros (1924, p.30) aponta os obstáculos e as batalhas que teve de enfrentar no Rio de Janeiro (DF): "Trago para a direção da Higiene do meu Estado uma alma formada na luta, 
um espírito de quem viveu muito entre livros e pelejas e conhece pálidas vitórias mas, também, já experimentou as amarguras que seguem as batalhas não vencidas; um coração de quem já sentiu a justiça e a injustiça e ficou, por isso, alheio às paixões, acima das falsas honrarias que vêm com os cargos e com os cargos se vão".

Acreditamos que uma das dificuldades por ele encontradas foi a oposição da repartição sanitária federal em relação às instituições particulares, que não se enquadravam no âmbito das organizações de saúde pública. A esse respeito, Fontenelle (1922, p.450) relata que:

\begin{abstract}
As instituições particulares, que devem ter a seu cargo as medidas de assistências e de cura: distribuição de alimentos e de roupas, tratamento sanatorial, etc., que constituem o lado social da questão, e as organizações de Saúde Pública que se encarregarão da parte sanitarial propriamente dita. Exigirá essa, além do serviço de enfermeiras de Higiene, a criação de dispensários, de hospitais de isolamento para os casos adiantados e de preventórios infantis.
\end{abstract}

Diante desse discurso, acreditamos que o serviço sanitário, que tinha como tarefas a visita domiciliar e a formação de enfermeiras visitadoras, ficou sob a responsabilidade do DNSP. Já as medidas sociais ficaram a cargo da Cruz Vermelha Brasileira (instituições particulares). Com essa tentativa de modificar as funções da instituição - sobretudo em relação ao Curso de Enfermeiras Visitadoras - ela provavelmente perderia o seu caráter científico e profissionalizante, tornando-se apenas um prestador de serviços sociais, o que acarretaria perda de espaço no campo da saúde pública e do ensino de enfermagem.

O campo é um sistema de relações objetivas entre posições adquiridas em lutas anteriores. É o lugar e o espaço no qual ocorre uma luta concorrencial. No campo da saúde pública, estavam em jogo os monopólios da autoridade científica (capacidade técnica e poder social) e de sua competência (capacidade de falar e de agir legitimamente, isto é, de maneira autorizada e com autoridade), que são socialmente consentidos a um agente ou a determinada instituição (Bourdieu, 2004).

Além disso, a tuberculose tornou-se uma questão social do Estado a partir da década de 1920. Antes desse período, eram as instituições filantrópicas que a combatiam, através dos seus dispensários próprios. Quando o governo federal assumiu a "questão da tuberculose"3 e traçou políticas sanitárias para minimizar o alto índice de morbimortalidade, o campo da saúde pública tornou-se uma arena de interesses e de acordos visando encontrar soluções para esse problema. A instituição ou o agente que conseguisse resolver essa questão obteria um lucro simbólico importante: poder e prestígio institucional, reconhecimento e visibilidade pública.

Ressaltamos também a influência do diretor do DNSP, Carlos Chagas. Ao visitar e conhecer os serviços da Cruz Vermelha Brasileira, ele sugeriu modificações, como se pode ver a seguir:

O ilustre cientista Dr. Carlos Chagas, Diretor do Departamento Nacional de Saúde Pública, logo após a sua chegada dos Estados Unidos da América do Norte, onde teve oportunidade de, pessoalmente, verificar a soma de serviços de que é capaz a CRUZ VERMELHA daquele país, entrou em entendimento com a Diretoria a fim de obter a colaboração da nossa Sociedade nos serviços públicos e de profilaxia a cargo daquele Departamento, ficando também resolvido fazer-se uma remodelação no ensino da Escola de Enfermeiras (Cruz Vermelha Brasileira, 1923, p.48). 
Apesar das considerações que Carlos Chagas fez em relação aos serviços prestados pelo Departamento de Profilaxia Contra a Tuberculose e por outros departamentos da Cruz Vermelha Brasileira, o histórico dessa instituição (Cruz Vermelha Brasileira, 1923, p.48) registra: "O Departamento de Profilaxia da Tuberculose e das Doenças Venéreas, a cargo da Cruz Vermelha, ia concorrendo largamente para a propaganda desta Sociedade, cujo nome e símbolo emblema se tornavam cada vez mais familiares à população". Apesar do movimento contrário, essa sociedade continuou capitalizando poder e prestígio social no campo da saúde pública e manteve a Escola de Enfermeiras.

No entanto, Carvalho (1976, p.6) afirma que "os produtos de todas essas louváveis realizações não foram, porém, da qualidade desejada pelos médicos do Departamento Nacional de Saúde Pública, nem considerados adequados às necessidades da situação então vigente". Ademais, o artigo 455, do decreto n.14.354, de 15 de setembro de 1920, do Regulamento do DNSP, por exemplo, dispunha que "nenhuma instituição para tratamento, isolamento ou socorro dos doentes de tuberculose poderá funcionar sem licença da Inspetoria de Profilaxia da Tuberculose" (Brasil, 15 set. 1920, p.340).

Percebe-se, assim, que a Cruz Vermelha Brasileira e outras instituições filantrópicas estavam subordinadas às boas ordens e ao poder político do DNSP. Segundo Bourdieu (2004, p.165), "o Estado é o detentor do monopólio da violência simbólica legítima, ou mais precisamente, um árbitro, entretanto muito poderoso, na luta por esse monopólio".

Além disso, o regulamento também interferia na vigilância higiênica e na contratação de enfermeiros e enfermeiras visitadoras:

\footnotetext{
A vigilância dos doentes de tuberculose em domicílio será feita especialmente pelas Enfermeiras Visitadoras, sob a superintendência dos médicos da Inspetoria de Profilaxia da Tuberculose. Os enfermeiros e as Enfermeiras Visitadores só serão admitidos quando possuírem diplomas da Escola de Enfermeiros do Departamento ou depois de aprovados em exame perante a Inspetoria de Profilaxia da Tuberculose ... E para o exame de que trata este artigo, só poderão se inscrever as pessoas que forem julgadas de boa saúde pela Inspetoria de Profilaxia da Tuberculose e possuírem as qualidades físicas e morais convenientes ao exercício da profissão a juízo da Inspetoria, com recurso para o Diretor Nacional da Saúde Pública (Brasil, 15 set. 1920, p.341-342).
}

Dessa forma, conforme o texto citado, se, por um lado, mais uma vez, o DNSP tentou manter o monopólio sobre a questão das enfermeiras visitadoras, por outro, abriu discretamente as portas para que outras pessoas ingressassem no serviço por meio de uma prova. Inferimos daí que o fato de haver enfermeiras diplomadas pela Cruz Vermelha Brasileira no quadro de pessoal do DNSP ${ }^{4}$ influenciou a aceitação de outras profissionais externas na Escola de Enfermeiros desse departamento. Uma delas, já integrante da instituição, era Edith Magalhães Fraenkel, que atuava como enfermeira-chefe da Inspetoria de Profilaxia da Tuberculose e, provavelmente, serviu como ponte entre a Cruz Vermelha Brasileira e o DNSP, o que contribuiu para a elaboração das bases dos Cursos de Enfermeiras Visitadoras dessa instituição.

Portanto, assim como a Cruz Vermelha Brasileira, o DNSP - pela ação da Inspetoria de Profilaxia da Tuberculose - logo tratou de formar enfermeiras visitadoras, sob a liderança de José P. Fontenelle. Diante disso, Fraenkel (1934, p.14) afirma: "Não existindo ainda no 
nosso país profissionais preparadas para esse fim, nem escola capaz de formá-las, procurou a Inspetoria de Profilaxia da Tuberculose preencher essa lacuna, criando um corpo provisório de visitadoras...".

Nesse discurso, observamos a censura da autora em relação a outra iniciativa de formação de enfermeiras visitadoras. Nos livros produzidos por Medeiros (1924, 1926), no Histórico da Cruz Vermelha Brasileira (Cruz Vermelha Brasileira, 1923), bem como na Revista BrazilMedico, na Revista da Semana e no boletim da Liga das Sociedades da Cruz Vermelha, está registrada a existência de outro Curso de Enfermeiras Visitadoras. Sabemos que, desde julho de 1920, já havia, no Rio de Janeiro (DF), profissionais pertencentes à Cruz Vermelha Brasileira que realizavam visitas domiciliares aos acometidos pela tuberculose.

No fragmento a seguir, publicado por José P. Fontenelle (1941, p.8), identificamos o mesmo discurso de Fraenkel. No texto, o sanitarista declarou-se o 'proclamador' das enfermeiras visitadoras: "O moderno programa de luta contra essa doença, que eu traçara através de vários artigos publicados em 1919 e 1920, levara o Dr. Plácido Barbosa, que iria chefiar o serviço de tuberculose, a convidar-me para ser seu assistente e juntos estudarmos os dispositivos do futuro Regulamento, introduzindo aí 'a alta novidade' das Enfermeiras Visitadoras especializadas no trabalho contra tal doença".

José P. Fontenelle e Fraenkel quiseram legitimar o Curso de Enfermeira Visitadora produzido pela Inspetoria de Profilaxia da Tuberculose do DNSP. Seus discursos opunhamse à outra diligência, a da Cruz Vermelha Brasileira. A esse respeito, Ortiz (2003) afirma que a língua não é somente um instrumento de comunicação ou conhecimento, mas de poder. Assim, por meio de seus escritos, eles conseguiram reconhecer e legitimar o Curso de Enfermeira Visitadora idealizado por J.P. Fontenelle.

Desse modo, alguns historiadores da enfermagem como Sauthier e Barreira (1999) reproduziram esse pensamento ao afirmar que J.P. Fontenelle foi o principal crítico da missão de cooperação técnica para o desenvolvimento de enfermagem no Brasil e também o maior defensor da ideia das enfermeiras visitadoras. Junto com o diretor da Inspetoria de Profilaxia da Tuberculose do DNSP e auxiliado pelos médicos da inspetoria, procurou preencher a lacuna dessas profissionais, criando um corpo provisório.

Sendo assim, as primeiras produções da história da enfermagem, relacionadas a essa questão, procuraram difundir a ideia de que J.P. Fontenelle foi o primeiro sanitarista a desenvolver o Curso de Enfermeira Visitadora no Rio de Janeiro (DF). No entanto, a presente investigação vem acrescentar à história da enfermagem mais uma interpretação sobre uma iniciativa pioneira na formação das enfermeiras visitadoras, atenuando o efeito de ocultamento, até então vigente na história da profissionalização da disciplina.

\section{A luta simbólica: as estratégias e alianças empreendidas para o monopólio do Curso de Enfermeiras Visitadoras}

É evidente que ambos os Cursos de Enfermeiras Visitadoras ocorreram em 1920 e no mesmo espaço geopolítico, mas em instituições e com idealizadores distintos. Esse fato confirma a existência de uma luta simbólica entre as primeiras (Cruz Vermelha Brasileira e o DNSP) e os segundos (Amaury de Medeiros e José P. Fontenelle) no campo da saúde 
pública. Segundo Bourdieu (2007), o princípio do campo reside no movimento perpétuo de lutas produzidas por suas estruturas constitutivas, e suas hierarquias residem nas ações e reações do agente. É justamente no campo, nesse jogo de forças, que o capital é incrementado, dando origem a concorrências derivadas das lutas internas. Desse modo, no campo da saúde pública, a questão em jogo nessa luta simbólica seguramente era a de quem ficaria com a responsabilidade de formação das enfermeiras visitadoras.

Por um lado, inferimos que o capital político e cultural que o agente Amaury de Medeiros detinha não foi suficiente para que o Curso de Enfermeiras Visitadoras da Cruz Vermelha Brasileira fosse mantido. O referido curso não construiu bases normativas e legítimas para se manter em funcionamento, principalmente após a saída do sanitarista da Cruz Vermelha Brasileira do Rio de Janeiro (DF).

Por outro lado, além do capital cultural e político que possuía, José P. Fontenelle era funcionário de uma repartição sanitária federal, o que nos leva a crer que esse fato o favoreceu a ocupar uma posição privilegiada no campo da saúde pública, garantido para si um lugar a partir do qual pudesse exercer seu poder simbólico. Segundo Pereira Neto (2001), o higienista José P. Fontenelle teve uma longa trajetória profissional no interior desse campo, desempenhando funções e ocupando cargos de prestígio, tendo sido o fundador do primeiro curso para formação de médicos sanitaristas no Rio de Janeiro (DF). Além disso, organizou o serviço de visitação domiciliar da Inspetoria de Profilaxia da Tuberculose do DNSP e contribuiu para a criação do Curso de Enfermeiras Visitadoras desse mesmo departamento, entre outras realizações.

Quando Plácido Barbosa viajou para os Estados Unidos, no final de 1920, José P. Fontenelle ficou responsável pela direção da Inspetoria de Profilaxia da Tuberculose, iniciando, sem demora (em novembro de 1920), um curso de instrução de emergência, com duração de dois meses, para formar as enfermeiras visitadoras, conforme o decreto n.14.354, de 15 de setembro de 1920 (Fontenelle, 1941). Vale enfatizar que as mudanças ocorridas nos serviços sanitários federais por meio desse decreto - como a introdução das enfermeiras nas inspetorias de profilaxias - proporcionaram a possibilidade de novos agentes serem inseridos em uma repartição pública federal.

Outro ponto relevante foi a aliança política que José P. Fontenelle mantinha com Carlos Chagas, detentor de um capital político, cultural e científico capaz de manter o Curso de Enfermeiras Visitadoras. Tais alianças simbólicas funcionam como estratégias para a obtenção de uma melhor posição no campo ou para a manutenção de suas estruturas em favor dos interesses em jogo no campo da saúde pública no Rio de Janeiro (DF).

Segundo Fraenkel (1934), apesar de toda a animação e esforço das enfermeiras visitadoras do DNSP, faltava-lhes os conhecimentos básicos de enfermagem. Por essa razão, o trabalho foi considerado pouco produtivo. Diante disso, Carlos Chagas requisitou à Fundação Rockefeller enfermeiras de saúde pública americanas para treinar as agentes que estavam alocadas na Inspetoria de Profilaxia da Tuberculose desse departamento. Logo, a luta simbólica entre esses agentes impulsionou a requisição de profissionais de enfermagem do exterior, com a finalidade de agregar valor ao Curso de Enfermeira Visitadora do DNSP.

José P. Fontenelle (1922, p.456-457) complementa a esse respeito: "Um dos mais importantes frutos da viagem de Carlos Chagas aos Estados Unidos foi a verificação do 
imenso valor das enfermeiras de Higiene, para os trabalhos de Saúde Pública, e a decisão trazida de ampliar muito o serviço iniciado, aumentando o quadro dessas subalternas e assegurando de melhor modo sua instrução técnica".

Carlos Chagas detinha capital simbólico adquirido nas lutas anteriores, além do título de sanitarista e do cargo de diretor de uma repartição pública federal, atribuições que lhe conferiram o direito e o poder simbólico necessários para requisitar uma contribuição internacional, a da Fundação Rockefeller, cuja finalidade era a capacitação do novo grupo de profissionais de saúde que estava sendo formado: o da enfermeira visitadora.

A Fundação Rockefeller ${ }^{5}$ procurou cooperar e encaminhou um grupo inicial de seis instrutoras norte-americanas - lideradas por Mrs. Ethel Parsons - com o intuito de melhorar os serviços de enfermagem e capacitar o grupo de enfermeiras visitadoras existentes (Fraenkel, 1934). Sendo assim, a liderança do Curso de Enfermeiras Visitadoras do DNSP foi herdada por ela.

A visita de Parsons objetivava a realização de um estudo sobre a enfermagem no país, no intuito de apresentar uma solução eficaz e desenvolver o serviço público de enfermagem. Ela se encontrou com quarenta senhoras que realizavam visitas domiciliares e, sobre esse encontro, teceu o seguinte comentário: "Essas moças não haviam tido preparo algum, e por mais fiéis e conscienciosas que fossem, e por mais que se esforçassem, os resultados de seus trabalhos não haviam sido satisfatórios para os seus chefes" (Parsons, 1997, p.14).

Nos escritos de Moreira (1998/1999, p.627), encontramos um trecho no qual Parsons acrescenta ainda: "Subordinada ao Departamento Nacional de Saúde, havia uma escola de enfermagem (para homens e mulheres), onde era oferecido um curso de dois anos sobre a tuberculose, higiene infantil e doenças venéreas. ... Os requisitos para admissão consistiam em possuir um baixo grau de instrução e pagar uma pequena anuidade. Não havia livrotexto, e a maioria dos alunos não sabia ler e nem escrever. Esse curso foi interrompido no final de 1921".

Ao se levar em conta que, nessa escola, o número de mulheres era superior ao de homens, depreende-se a carência de habitus primários dos estudantes, uma vez que o grau de instrução era baixo, e a maioria não sabia ler nem escrever. Na verdade, o ensino estava preparado para oferecer uma formação mais apropriada aos rapazes, sendo bastante deficiente para as moças. Segundo Beltrão e Alves (2009), durante a maior parte do século XX, houve um hiato de gênero na educação brasileira, pois as taxas de alfabetização e os demais índices de educação do sexo masculino eram superiores aos do feminino.

Entretanto, cabe destacar que, apesar de Parsons ressaltar a existência de uma Escola de Enfermagem para homens e mulheres, ao analisar as propostas dos Cursos de Enfermeiras Visitadoras idealizados pelo sanitarista Amaury de Medeiros e por J.P. Fontenelle, constatamos que ambos se basearam na feminização do cuidado em saúde pública, a partir da qual a figura do homem provavelmente deixou de ser admitida - já que não encontramos a menção a qualquer nome masculino nas listas dos inscritos no curso de enfermeiras visitadoras. Nesse espaço, as aptidões inerentes ao gênero feminino foram destacadas por esses agentes e, de certa forma, aproveitadas para dominá-las. Naquela época, a sociedade era organizada androcentricamente, e as características das mulheres ratificavam a dominação masculina, estando inscritas no mais íntimo dos corpos das enfermeiras visitadoras. 
Além disso, no artigo 1.194 do decreto n.14.354 constava que, até um ano após a data de publicação do regulamento do DNSP em Diário Oficial, o governo federal poderia fazer modificações: "Pode o Governo fazer nele as alterações que a prática demonstrar necessárias à maior eficiência dos serviços peculiares ao Departamento, ficando tais alterações incorporadas, para todos os efeitos..." (Brasil, 15 set. 1920, p.470).

Com a finalidade de manter as enfermeiras de saúde pública americanas, lideradas por Parsons, na repartição sanitária do DNSP, o diretor Carlos Chagas, à luz do decreto n.15.003, promoveu, em 15 de setembro de 1921, algumas mudanças no regulamento, entre elas: "Foi autorizada a organização de um quadro de enfermeiras de Higiene, aproveitando-se para esse fim a redução de despesas proveniente da diminuição futura do número de inspetores sanitários, e para o que foram contratadas instrutoras americanas" (Fontenelle, 1922, p.446).

Vale destacar que, nesse decreto, com força de lei, estava em jogo o poder de impor a necessidade da figura da enfermeira no DNSP e de reconhecer a legitimidade de sua presença em uma repartição do Estado. Sobre esse propósito, Bourdieu (2007, p.114) comenta: "Esse ato de direito, que consiste em afirmar com autoridade uma verdade que tem força de lei, é um ato de conhecimento, o qual, por estar firmado, como todo o poder simbólico, no reconhecimento, produz a existência daquilo que enuncia".

Esse episódio traz à tona o poder e o prestígio político e social que a enfermeira Parsons detinha, bem como o valor dado às enfermeiras visitadoras - até porque os médicos, em número excessivo, foram gradativamente substituídos por um grupo de enfermeiras norteamericanas. O trabalho dessas profissionais em uma repartição sanitária federal permitiu, assim, a conquista de espaços de autonomia e legitimidade diante da hierarquia médica.

Para atender à necessidade imediata do DNSP, Parsons ofereceu um Curso de Emergência de seis meses para as enfermeiras visitadoras que atuavam na Inspetoria de Profilaxia da Tuberculose. O curso teve início em abril de 1922 e terminou em outubro do mesmo ano. Sua proposta foi oferecer pequenas noções para essas mulheres desenvolverem um trabalho padronizado, pois a ideia inicial de Parsons era a de investir na instrução de Enfermeira em Saúde Pública. Diante disso, com o apoio e incentivo de Carlos Chagas, foi instalada uma escola (atual Escola de Enfermagem Anna Nery) anexa ao Hospital São Francisco de Assis (Parsons, 1997).

É nesse contexto que pudemos evidenciar a posição de destaque ocupada por Carlos Chagas no campo da saúde pública. Foi seu prestígio, conhecimento e reconhecimento no campo que viabilizaram a articulação da vinda dessas enfermeiras para fundar uma nova Escola de Enfermagem, baseada no modelo de Parsons e sob influência da enfermagem moderna.

Entretanto, o quantitativo de enfermeiras visitadoras não foi suficiente para atender à demanda dos serviços em saúde pública do DNSP. Os inspetores do departamento fizeram pressão sobre Parsons para que realizasse outro Curso de Emergência, pois não poderiam esperar pela formação das futuras enfermeiras em saúde pública (Parsons, 1997). A necessidade premente de enfermeiras visitadoras para trabalhar nos distritos e a longa duração do curso da Escola de Enfermeiras do DNSP forçaram a instalação de outro Curso de Emergência. 
Para atender ao pedido dos sanitaristas, Parsons organizou um curso com duração de dez meses para enfermeiras visitadoras, repetido por mais duas vezes. O mesmo outorgou às estudantes um certificado que lhes garantiu, mais tarde, a continuação no curso da Escola de Enfermeiras do DNSP (Parsons, 1997). Dessa forma, elas conquistariam o direito de se formar enfermeiras diplomadas em saúde pública.

No entanto, os Cursos de Emergência constituíam uma preocupação para Parsons (1997, p.15), no sentido de que: "Poderia ter posto em perigo, por muitos anos, os padrões de educação da profissão de enfermeiras... Os médicos e as autoridades reconheceram claramente ter sido o plano do curso de emergência de dez meses realmente uma medida temporária e de emergência para atender às necessidades do momento, e que, não podendo esse curso preparar as alunas pelo padrão elevado de serviço desejado. Teria, por força, de ser aperfeiçoado e prolongado o mais breve possível".

A partir da leitura do trecho acima, fica evidente o posicionamento de Parsons contra as enfermeiras visitadoras. Segundo ela, estas últimas não seriam suficientemente preparadas para assumir cargos de responsabilidade no campo da saúde pública e, por essa razão, deveriam trabalhar como auxiliares das enfermeiras de saúde pública.

Fraenkel (1934), por sua vez, assinalou que os chefes das inspetorias não consideravam mais necessária a realização de Cursos de Emergência. Segundo a autora, os chefes poderiam esperar pelas enfermeiras diplomadas, especialmente capacitadas para o serviço de saúde pública. Eles consideravam que as enfermeiras visitadoras eram preparadas de maneira insuficiente e superficial. Sendo assim, o Curso de Emergência não foi novamente ministrado, e as enfermeiras visitadoras foram gradativamente substituídas pelas enfermeiras de saúde pública.

Fica evidente aqui a que ponto as questões de hierarquia profissional e àquelas relativas à capacidade técnica antagonizaram, de certa forma, as enfermeiras visitadoras e as enfermeiras diplomadas de saúde pública. Com o decorrer dos anos, a liderança profissional dessas enfermeiras diplomadas da Escola de Enfermeiras do DNSP foi legitimada e tornouse inquestionável. As enfermeiras visitadoras, por sua vez, foram caracterizadas como profissionais auxiliares, uma vez que lhes faltava capital cultural, conforme os discursos de Fraenkel e Parsons.

Desse modo, José P. Fontenelle obteve um lugar de maior destaque no campo, sendo reconhecido e considerado o idealizador das enfermeiras visitadoras no Rio de Janeiro (DF). Com isso, manteve o Curso de Enfermeiras Visitadoras no DNSP, que passou para o domínio e controle da enfermeira Parsons. Já Amaury de Medeiros, cujo nome foi omitido nas primeiras produções da história da enfermagem, foi o pioneiro e um importante agente defensor destas profissionais. Coube a ele ser o depositário de uma crença na saúde pública e nessas agentes.

Diante desse jogo de forças, após ser convidado pelo então governador de Pernambuco, Sergio Loreto, para assumir a direção dos serviços sanitários do estado, Amaury de Medeiros saiu estrategicamente do campo da saúde pública do Rio de Janeiro (DF) para Recife (PE), onde a competição seria menos forte. $\mathrm{O}$ resultado desse jogo viria mais tarde.

Ao ocupar a liderança do DSA de Pernambuco, Amaury de Medeiros fez inúmeras modificações, como as reproduzidas a seguir: 
pela Lei 1.569, de 11 de maio de 23, que o Departamento de Saúde Pública se tornasse autônomo, diretamente subordinado ao gabinete do Governador do Estado, libertandose, pois, da Secretaria Geral do Estado. Amaury enfeixava, ainda por cima, por força de convênios, atribuições de serviços federais. Isso colocava a Saúde Pública, no Pernambuco daquele tempo, em condições excepcionais de viabilidade e eficiência, permitindo à sua chefia um poder de direção de que nenhum outro setor administrativo dispunha na época. Amaury jogava, ademais, com um título exclusivo, que somente empregava em benefício do seu programa sanitário: o de genro do governador. Essa circunstância lhe conferia um prestígio imensurável: o de agir ou, pelo menos, fazer supor que agia em nome do Governo, cuja responsabilidade ficava naturalmente implicada em qualquer de suas decisões (Oliveira, 1975, p.28).

Diante desse discurso, é notório o capital simbólico que Amaury de Medeiros detinha e o poder - obtido por meio da posse desse capital - de ocupar mais de uma posição no campo da saúde pública em Pernambuco. Cabe destacar que esse sanitarista estava diretamente ligado ao governador, seu sogro. Bourdieu (2007) adverte que a adoção do nome de família representa um conjunto de indivíduos aparentados ligados entre si por aliança, casamento e filiação, o que transmite capital simbólico hereditário, conferindo poder e prestígio.

Desse modo, aproveitando-se de sua posição no campo político e da saúde pública, e com a finalidade de reduzir o índice de morbimortalidade da tuberculose, melhorar a assistência infantil e acrescentar outras atividades como obstetrícia, odontologia e venereologia em Pernambuco, Amaury de Medeiros aprimorou e ampliou a proposta pedagógica do Curso de Enfermeira Visitadora, obtendo sucesso, conforme as palavras de Oliveira (1975, p.47): "O curso de visitadoras teve ampla repercussão, abrindo novas perspectivas à mulher, pela primeira vez admitida ao serviço sanitário...".

Amaury de Medeiros levou a ideia do Curso de Enfermeiras Visitadoras para o Recife (PE), com grande êxito. Oliveira (1975, p.47) assinala a esse respeito: “... A criação do corpo de Visitadoras da Saúde Pública, serviço que fundara e dirigira na Cruz Vermelha Brasileira, no Rio. A experiência que ali colhera o autorizava a repeti-la no Recife...". O próprio Medeiros (1926, p.184) acrescenta: "A experiência que tínhamos da instrução de enfermeiras na Cruz Vermelha Brasileira nos mostrou que devíamos levantar, por todos os meios, o nível moral, social e intelectual do serviço".

Nesse discurso, Amaury de Medeiros reconheceu as limitações do curso desenvolvido no Rio de Janeiro (DF) e a necessidade de reformulá-lo no Recife. Ele buscou constantemente o reconhecimento público para essas profissionais, considerando fundamental engrandecêlas por meio de um curso com bases sólidas, que formasse profissionais de alta qualificação.

No Departamento de Saúde e Assistência de Pernambuco, o sanitarista criou a Inspetoria de Profilaxia da Tuberculose, realizou um código sanitário e instituiu o Curso de Enfermeiras Visitadoras. Este último, cujo início ocorreu em abril de 1923, tinha como pré-requisito que a enfermeira visitadora fosse professora, farmacêutica, dentista ou parteira com diploma, além de contar com exames de moralidade e de educação (Medeiros, 1926).

Entendemos que essa modalidade de curso e suas exigências significaram um avanço em comparação ao primeiro curso idealizado e oferecido por Amaury de Medeiros na Cruz Vermelha Brasileira não somente em termos de qualidade, mas também porque, ao atender 
a esse pré-requisito, o próprio aproveitamento das candidatas seria melhor. Além disso, todas as mulheres que ingressaram no curso já apresentavam habitus profissional compatível com a área da saúde ou educação, fato que certamente favoreceu a adoção das atividades da enfermeira visitadora nos lares.

Enquanto isso, em outro espaço institucional - no DSA de Pernambuco - Amaury de Medeiros mantinha a extensão do seu movimento em relação ao Curso de Enfermeira Visitadora. No DNSP, Parsons, por sua vez, manteve seus esforços para extinguir o cargo de enfermeira visitadora e substituí-la pelas futuras enfermeiras diplomadas para atuar na saúde pública.

A enfermeira Parsons e o sanitarista Amaury de Medeiros apresentavam outra distinção, relativa à denominação conferida a essas profissionais. A primeira, assim que chegou ao Brasil e assumiu a Superintendência Geral do Serviço de Enfermeiras, alterou o nome de enfermeira visitadora para visitadoras de higiene, de acordo com seus escritos. Na verdade, Parsons buscava elementos de distinção entre a enfermeira visitadora, subalterna ao médico, conforme o discurso de José P. Fontenelle, e a futura enfermeira de saúde pública, diplomada pela Escola de Enfermeiras do DNSP. Além disso, Parsons não queria que essas futuras profissionais estivessem em condições análogas e comungassem disposições e interesses semelhantes aos das enfermeiras visitadoras. Ela vislumbrava disposições distintas para cada grupo profissional e a própria extinção de cargo de enfermeira visitadora.

Ademais, a "distinção social não é um processo homogêneo, mas opera através da apropriação dos bens simbólicos, em função da posição de classe e do capital cultural dos indivíduos", nos lembra Ortiz (2003, p.28). Sendo assim, as futuras enfermeiras de saúde pública seriam detentoras de um capital cultural mais expressivo do que as enfermeiras visitadoras, pois o curso de 28 meses abordava diversas matérias que o curso de formação destas últimas não contemplava.

O pensamento de Amaury de Medeiros era distinto: para o sanitarista, a palavra enfermeira proporcionava uma impressão de submissão. Para evitar essa conotação, ele defendia a imagem das visitadoras de saúde pública, uma vez que o termo apresentava um sentido mais forte. Por esta razão, denominou-as visitadoras: “Anunciei um curso que denominei não de enfermeira, mas de visitadoras, para tirar a impressão servil que esse nome poderia ter..." (Medeiros, 1926, p.184). Evidencia-se, assim, sua preocupação em melhorar a imagem da enfermeira visitadora, por meio de um curso com outra proposta pedagógica e com maior poder de capacitação e autonomia.

Nas palavras de Bourdieu: “Todas as práticas estão orientadas para a aquisição de autoridade científica (prestígio, reconhecimento, celebridade), o que chamamos comumente de 'interesse' por uma atividade científica (uma disciplina, um setor dessa disciplina, um método) tem sempre dupla face" (Ortiz, 2003, p.114). Com base no pensamento de Bourdieu, o comportamento e o discurso de Amaury de Medeiros para com as enfermeiras visitadoras nos conduzem à formação de duas hipóteses. Por um lado, seu ideal estava diretamente relacionado com a questão dos serviços sanitários, que chefiava no DSA de Pernambuco. Naquela instituição, o trabalho da enfermeira visitadora se tornaria indispensável para o pleno funcionamento da repartição sanitária por ele liderada. Numa outra acepção, as 
aspirações do sanitarista eram realmente que essas profissionais conquistassem espaços de autonomia e legitimidade diante da sociedade e do campo da saúde pública.

Enfim, os discursos desses agentes foram opostos, levando-os a movimentos diferentes em cada espaço social. No Rio de Janeiro (DF), o Curso de Enfermeira Visitadora foi eliminado do DNSP. No entanto, essas agentes continuaram atuando em diversos âmbitos, como descrito em alguns estudos. Campos (2007) menciona os serviços de atenção básica no Brasil, referindo-se ao fato de que o Centro de Saúde de Inhaúma, inaugurado em janeiro de 1927, contava com um serviço de enfermeiras visitadoras.

Já em Pernambuco, mesmo com a saída do sanitarista do DSA, para assumir o cargo de deputado federal no Rio de Janeiro (DF), o curso conseguiu manter-se no governo de Estácio Coimbra (1926-1930), quando foi estendido e transformado no Curso de Educação Sanitária (Abrão, 2006).

Amaury de Medeiros delineou os primeiros passos para o ensino de enfermagem, contribuindo para que as mulheres obtivessem um capital simbólico institucionalizado, isto é, o título profissional de enfermeiras visitadoras. Além do bem social coletivo obtido, a atuação dessas agentes deu visibilidade ao grupo e fortaleceu sua credibilidade junto à sociedade. Desse modo, Amaury de Medeiros conseguiu instituir as bases para a formação incipiente de enfermeiras no estado de Pernambuco.

\section{Considerações finais}

A formação das enfermeiras visitadoras traz à luz a questão da luta simbólica entre os agentes Amaury de Medeiros e José P. Fontenelle e as instituições sanitárias e filantrópicas. O que estava em discussão era quem teria a autoridade e a competência científica necessárias para formar estas profissionais, então consideradas fundamentais para a prática da educação sanitária, a redução da contaminação e a proliferação da tuberculose.

Mesmo ocupando espaços distintos, Amaury de Medeiros e José P. Fontenelle foram fundamentais para a inserção das enfermeiras visitadoras em instâncias federais. Entretanto, o capital político e cultural que o primeiro agente detinha não foi suficiente para manter o Curso de Enfermeiras Visitadoras na Cruz Vermelha Brasileira após a sua saída dessa instituição, para assumir o cargo de diretor do DAS em Pernambuco, onde manteve a extensão do seu movimento em prol das enfermeiras visitadoras. Por outro lado, o agente José P. Fontenelle, além de deter capital cultural, era funcionário do DNSP e aliado de Carlos Chagas, o que incrementou seu capital político. Logo, na balança de correlação de forças, José P. Fontenelle obteve o monopólio da decisão sobre a questão das enfermeiras visitadoras no DNSP.

Cabe destacar que, apesar de a enfermeira visitadora ter emergido sob o poder simbólico dos sanitaristas, a necessidade dessas agentes, seu conhecimento e reconhecimento foram decisivos para que as repartições sanitárias requisitassem, mediante cooperação internacional, a participação de enfermeiras do exterior para incrementar a formação das profissionais em questão.

Diante disso, o Curso de Enfermeira Visitadora do DNSP foi herdado por Ethel Parsons. Apesar de o curso ter sido ministrado quatro vezes, Parsons era contra a formação de 
enfermeiras visitadoras. De início, ela atendeu à solicitação dos sanitaristas e a usou como estratégia para acumular força política. Sua intenção era a de consolidar outros interesses no espaço do DNSP e na enfermagem brasileira.

Ademais, a posição ocupada pela enfermeira Parsons (de Superintendente do Serviço de Enfermeiras do Departamento) manteve as agentes enfermeiras visitadoras sob seu domínio. Ela adotou a estratégia de adesão por aproveitamento do habitus, ao garantir que as enfermeiras visitadoras receberiam o certificado que lhes permitiria continuar o curso da Escola de Enfermeiras do DNSP. Sendo assim, conferiu ao grupo a possibilidade de permuta da identidade profissional pelo ganho simbólico do diploma de enfermeira de saúde pública, denominação creditada às primeiras enfermeiras formadas pela escola, o que acabou efetivamente ocorrendo com parte das enfermeiras visitadoras.

Desse modo, Parsons evitou legitimar uma modalidade profissional, que igualmente exercia a enfermagem, no intuito de afastar sua ameaça para o grupo das enfermeiras diplomadas em um mesmo espaço institucional, o DNSP - até porque o regulamento desse departamento, com força de lei, legitimava a presença das enfermeiras visitadoras na repartição sanitária federal.

A partir das evidências aqui levantadas, é possível afirmar a existência de diversos desdobramentos a partir do funcionamento dos Cursos de Enfermeiras Visitadoras no Rio de Janeiro (DF), no decorrer dos anos 1920 e 1930. As iniciativas educativas proporcionaram a expansão do trabalho feminino na Primeira República e ampliaram a perspectiva da enfermagem no campo da saúde pública. Ademais, o investimento nas agentes sociais da enfermagem, por parte dos idealizadores dos cursos, revelou-se uma estratégia bemsucedida, que ampliou a inserção feminina no mundo do trabalho.

\section{NOTAS}

${ }^{1}$ Em 1763, a cidade do Rio de Janeiro tornou-se a capital do Brasil, título que manteve até 1960, quando Brasília foi inaugurada e passou a deter o título.

${ }^{2}$ Reportagem publicada na Revista Brazil-Medico, n.28, no dia 10 de julho de 1920, p.450, e publicada na Revista da Semana em 1920, p.23.

${ }^{3}$ Vários movimentos sanitários floresceram, na década de 1910 - com destaque para a Liga Pró-Saneamento (liderada por Belisário Penna) - com o objetivo de reformular os serviços de saúde, originando uma repartição sanitária com maior poder de intervenção. Até então, o serviço sanitário estava sob o comando da DGSP, e, com a reforma sanitária liderada por Carlos Chagas, em 1920, foi promulgada a reorganização dos serviços e instituído o DNSP por meio do decreto n.3.987, de 2 de janeiro de 1920. Carlos Chagas, diretor do DNSP, teve de apresentar um código sanitário, divulgado em 15 de setembro de 1920 e denominado "Regulamento do DNSP".Por meio deste último foi criada a Inspetoria de Profilaxia da Tuberculose, que objetivava a profilaxia da enfermidade no Rio de Janeiro (DF). A direção dessa inspetoria ficou sob a responsabilidade de Plácido Barbosa, que teve como assistente José P. Fontenelle. Essa inspetoria indicou um avanço da responsabilidade do Estado na questão da tuberculose. Para mais detalhes, consultar Fontenelle, 1922; 1941.

${ }^{4}$ Duas enfermeiras visitadoras foram para o DNSP: Violeta Martins e Idália de Araújo Porto Alegre. Para mais detalhes, consultar Cruz Vermelha Brasileira, 1923.

${ }^{5}$ A Fundação Rockefeller desempenhou um papel fundamental no processo de valorização e na criação do campo da enfermagem de saúde pública no Brasil. Para mais detalhes, pesquisar em Faria, 1995. 


\section{REFERÊNCIAS}

ABRÃO, Fátima Maria da Silva. Primórdios da enfermagem profissional na cidade do Recife - Pernambuco: raízes da préinstitucionalização da formação do campo organizacional (1922-1938). Tese (Doutorado) - Escola de Enfermagem de Ribeirão Preto, Universidade de São Paulo, Ribeirão Preto. 2006.

BELTRÃO, Kaizô Iwakami; ALVES, José Eustáquio Diniz.

A reversão do hiato de gênero na educação brasileira no século XX. Cadernos de Pesquisa, São Paulo, v.39, n.136, p.125-156. 2009.

BOURDIEU, Pierre.

O poder simbólico. Rio de Janeiro: Bertrand Brasil. 2007.

BOURDIEU, Pierre.

Coisas ditas. São Paulo: Brasiliense. 2004.

BOURDIEU, Pierre.

A dominação masculina. Rio de Janeiro: Bertrand Brasil. 1999.

BRASIL.

Decreto n.14.354, de 15 de setembro de 1920. Dispõe sobre o regulamento para o Departamento Nacional de Saúde Pública, em substituição do que acompanhou o decreto n.14.189, de 26 de maio de 1920. Atos do Poder Executivo. Diário Oficial da União. Rio de Janeiro, p.244-485. 15 set. 1920.

CAMPOS, Carlos Eduardo Aguilera. As origens da rede de serviços de atenção básica no Brasil: o Sistema Distrital de Administração Sanitária. História, Ciências, Saúde - Manguinhos, Rio de Janeiro, v.14, n.3, p.877-906. 2007.

CARVALHO, Anayde Corrêa de. Associação Brasileira de Enfermagem 1926-1976. Brasília: Associação Brasileira de Enfermangem. Documentário Anayde Corrêa de Carvalho. 1976.

CRUZ VERMELHA BRASILEIRA.

Histórico da Cruz Vermelha Brasileira (19081923). Rio de Janeiro: Órgão Central. 1923.

CRUZ VERMELHA BRASILEIRA.

Revista Brazil-Medico, Rio de Janeiro, ano 24, n.28, p.450-451. 1920.

\section{CRUZADA NACIONAL CONTRA A}

TUBERCULOSE.

Revista da Semana, Rio de Janeiro, ano 24, n.16. 1923.

FARIA, Lina Rodrigues de.

Os primeiros anos da reforma sanitária no

Brasil e a atuação da Fundação Rockefeller
(1915-1920). Physis, Rio de Janeiro, v.5, n.1, p.109-129. 1995.

FONTENELLE, José P.

A enfermagem de saúde pública: sua creação e desenvolvimento no Rio de Janeiro. Rio de Janeiro: Canton \& Reile. 1941.

FONTENELLE, José P.

Diccionario historico, geographico e ethnographico do Brasil. Dispõe sobre diversas monografias completas sobre o Brasil em geral e sobre cada um dos estados. Rio de Janeiro: Imprensa Nacional. 1922.

FRAENKEL, Edith de Magalhães.

Histórico do serviço de enfermeiras do Departamento Nacional de Saúde Pública. Annaes de Enfermagem, Rio de Janeiro, v.2, n.4, p.14-17. 1934.

LEAGUE OF RED CROSS SOCIETIES.

Bulletin of the League of Red Cross Societies. v. 2 Geneva: League of Red Cross Societies. 1921.

LEITE, Mirian Moreira.

A outra face do feminismo: Maria Lacerda de Moura. São Paulo: Ática. 1984.

MEDEIROS, Amaury de. Saúde e assistência: doutrinas, experiências e realizações 1923-1926. Recife: s.n. 1926.

MEDEIROS, Amaury de.

Cruzada sanitária: discursos. Recife: s.n. 1924.

MERHY, Emerson Elias.

O capitalismo e a saúde pública: a emergência das práticas sanitárias no estado de São Paulo. Campinas: Papirus. 1987.

MOREIRA, Martha Cristina Nunes.

A Fundação Rockefeller e a construção da identidade profissional de enfermagem no Brasil na Primeira República. História, Ciências, Saúde - Manguinhos, Rio de Janeiro, v.5, n.3, p.621-629. 1998/1999.

NASCIMENTO, Dilene Raimundo do. Fundação Ataulpho de Paiva. Liga Brasileira contra a Tuberculose: um século de luta. Rio de Janeiro: Quadratim. 2002.

OLIVEIRA, Valdemar.

No tempo de Amaury. Recife: Cepe. 1975.

ORTIZ, Renato (Org.).

A sociologia de Pierre Bourdieu. São Paulo: Olho D'água. 2003.

PAICHELER, Geneviève.

Presentation. Les profesions de soins: territoires et empietementes. Science Sociales et Santé. v.13. Paris: John Libbey Eurotex. p.5-10. 1995. 
PARSONS, Ethel.

A enfermagem moderna no Brasil. Escola Anna Nery Revista de Enfermagem, Rio de Janeiro, v.1, n.esp., p.10-24. 1997.

PEREIRA Neto, André de Faria.

Ser médico no Brasil: o presente no passado. Rio de Janeiro: Editora Fiocruz. 2001.
SAUTHIER, Jussara; BARREIRA, Ieda de Alencar.

As enfermeiras norte-americanas e o ensino da enfermagem na capital do Brasil: 1921-1931. Rio de Janeiro: Escola de Enfermagem Anna Nery/ UFRJ. 1999.

\section{$\rightarrow \rightarrow \rightarrow<<$}

